\title{
Introduction to a Special Section: Essential Fatty Acids in Fish
}

\section{David S. Francis}

School of Life and Environmental Sciences, Deakin University, Geelong, VIC 3220, Australia

\section{Mónica B. Betancor}

Institute of Aquaculture, Faculty of Natural Sciences, University of Stirling, Stirling FK9 4LA Scotland, United Kingdom

In an age of heavy fish oil substitution, knowledge relevant to the essential fatty acid (EFA) requirements of farmed fish species is paramount for effective feed formulation, marine resource utilisation and optimised on-farm production. Whilst the methodologies to assess these requirements have long been established, the practicalities of generating speciesspecific information for the $>350$ recognised finfish species produced via aquaculture (FAO, 2018) are borderline insurmountable and unjustified. To this end, the broader aquaculture community (comprising researchers, feed manufacturers, raw material producers, farmers etc) has made/ accepted a series of early generalisations/ simplifications that outline the dietary requirement for short chain polyunsaturated fatty acids ( $C_{18}$ PUFA) versus long chain polyunsaturated fatty acids (LC-PUFA) based on thermal and salinity preferences. Despite evidence of numerous exceptions to this 'rule', these assumptions have largely informed a host of formulation decisions in an absence of species-specific information and been indoctrinated throughout the sector.

In recognition of the need to develop more efficient predictive abilities for species-specific fatty acid requirements, it is with great pleasure that we present this Special Section on 'Essential Fatty Acids in Fish' compiled by Jesse Trushenski and colleagues. This body of work introduces the concept of using trophic level as a means of predicting the EFA requirements of fish, as initially proposed by Sargent et al. (1995) more than 25 years ago. Comprising a series of six articles, the topic is initially reviewed and the terms 'essential' and 'requirement' defined in the context of fatty acids, prior to highlighting the inaccuracies of basing the EFA requirements of a species on its thermal and salinity preferences (Trushenski and Rombenso 2020). The findings of five elegantly designed feeding trials assessing the essentiality of $C_{18}$ PUFA and LC-PUFA are subsequently presented and discussed for rainbow trout (Barry and Trushenski 2020a), channel catfish (Trushenski et al. 2020), Nile tilapia (Jackson et al. 2020a), Florida pompano (Jackson et al. 2020b) and hybrid stiped bass (Barry and Trushenski 2020b). Effectively spanning low, medium and high trophic level species, this collection of work confirms the improved accuracy of using trophic level to predict the essentiality of PUFA in fish species over that of temperature and salinity preference. In unison, these studies chart a far more reliable mechanism to predict the EFA requirements of fish species when the necessary qualitative and quantitative information are unavailable, offering a highly valuable and insightful contribution to the field of fish nutrition as it continues to delve deeper into marine resource substitution. 


\section{References}

FAO (Food and Agriculture Organization of the United Nations). 2018. The state of world fisheries and aquaculture. FAO, Rome.

Sargent, J. R., J. G. Bell, M. V. Bell, R. J. Henderson, and D. R. Tocher. 1995. Requirement criteria for essential fatty acids. Journal of Applied Ichthyology 11:183-198.

Trushenski J. T., and A. N. Rombenso. 2020. Fatty Acids in Fish-Introduction to a special section and a brief synthesis. North American Journal of Aquaculture. DOI: 10.1002/naaq.10137.

Barry, K. J., and J. T. Trushenski. 2020a. Reevaluating polyunsaturated fatty acid essentiality in Rainbow Trout. North American Journal of Aquaculture. DOI: 10.1002/naaq.10133.

Trushenski, J. T., A. N. Rombenso, and C. J. Jackson. 2020. Reevaluating polyunsaturated fatty acid essentiality in Channel Catfish. North American Journal of Aquaculture. DOI: 10.1002/naaq.10136.

Jackson, C. J., J. T. Trushenski, and M. H. Schwarz. 2020a. Reevaluating polyunsaturated fatty acid essentiality in Nile Tilapia. North American Journal of Aquaculture. DOI: 10.1002/naaq.10131.

Jackson, C. J., J. T. Trushenski, and M. H. Schwarz. 2020b. Assessing polyunsaturated fatty acid essentiality in Florida Pompano. North American Journal of Aquaculture. DOI: 10.1002/naaq.10140.

Barry, K. J., and J. T. Trushenski. 2020b. Reevaluating polyunsaturated fatty acid essentiality in hybrid Striped Bass. North American Journal of Aquaculture. DOI: 10.1002/naaq.10130. 